\title{
Mechanisms of SU5416, an inhibitor of vascular endothelial growth factor receptor, as a radiosensitizer for colon cancer cells
}

\author{
EUN HO KIM ${ }^{1}$, HANNA LEE ${ }^{1}$, YOUN KYOUNG JEONG ${ }^{2}$ and WON-GYUN JUNG ${ }^{1}$ \\ ${ }^{1}$ Division of Heavy Ion Clinical Research and ${ }^{2}$ Research Center for Radiotherapy, Korea Institute of Radiological \\ and Medical Sciences, Nowon-Ku, Seoul 139-706, Republic of Korea
}

Received December 23, 2015; Accepted February 26, 2016

DOI: 10.3892/or.2016.4868

\begin{abstract}
Colorectal cancer is one of the most common cancers worldwide. Previous studies suggest that chemoradiotherapy is more effective for the treatment of colorectal cancer than is radiotherapy or chemotherapy alone. To enhance the radiosensitivity of tumor cells, several investigators have used targeted therapeutic agents that act as radiosensitizers. In the present study, we provide a scientific rationale for the clinical application of SU5416, an inhibitor of vascular endothelial growth factor receptor-2, as a radiosensitizer for colorectal cancer. Two human colorectal adenocarcinoma cell lines, HCT116 and HT-29, were treated with SU5416 and radiation alone or radiation followed by SU5416. In vitro tests were performed using colony forming assays, flow cytometric analysis, immunohistochemistry, senescence-associated $\beta$-galactosidase, tumor cell motility and invasion assays. The combination of radiation and SU5416 synergistically inhibited cell survival and induced apoptosis through reactive oxygen species, enhanced IR-induced premature senescence, and inhibited DNA repair activity, cell migration and invasion. Collectively, our results favor the use of SU5416 and radiotherapy as a combination therapy for the treatment of colon cancer and it can be combined successfully with a radiation regimen to potentiate its antitumor and antimetastatic activities for future clinical trials.
\end{abstract}

\section{Introduction}

Colon cancer, the second major cause of cancer-related death in the US, has also become a common malignancy in Asia due to recent changes in diet. Individuals with colorectal cancer that has spread from the colon or rectum to other parts of the body often undergo chemotherapy or radiation using a combination

Correspondence to: Dr Eun Ho Kim, Division of Heavy Ion Clinical Research, Korea Institute of Radiological and Medical Sciences, 215-4 Gongneung-Dong, Nowon-Ku, Seoul 139-706, Republic of Korea

E-mail: eh140149@kirams.re.kr

Key words: SU5416, angiogenesis, colorectal cancer, invasion, radiosensitivity of targeted drugs to alleviate symptoms of the disease and reduce local failure and distant metastasis or prolong survival time, thereby improving the clinical outcome of patients $(1,2)$.

Vascular endothelial growth factor (VEGF) plays an essential role in the progression of cancer by stimulating the new growth of blood vessels (3). Essentially, VEGF stimulates the body to provide a blood supply for a newly developing cancer (4). SU5416 inhibits the effects of VEGF in the body and is now being evaluated in patients with metastatic colorectal cancer (5). The combination of radiotherapy and targeted drugs with anti-angiogenic or anti-vascular effects may be the most prospective approach to improving therapeutic anticancer results $(3,6,7)$.

In the present study, we investigated the enhancement of radiation-induced antitumor and antimetastatic effects in colorectal cancer cells induced by combination treatment with SU5416. We found that the addition of SU5416 markedly enhanced the therapeutic efficacy of radiation in colon cancer cells through an increase in apoptosis and inhibition of metastatic potential. Taken together, our results show that SU5416 can be successfully combined with a radiation regimen to potentiate its antitumor and antimetastatic activities. The present study provides a scientific rationale for further exploration of the efficacy of the combination of radiation and VEGF-targeted therapy in controlling the growth of colon cancer cells for future clinical trials.

\section{Materials and methods}

Antibodies and chemicals. Antibody against $\beta$-actin was purchased from Santa Cruz Biotechnology (Santa Cruz, CA, USA). Antibodies against phosphorylated extracellular signal-regulated kinase (p-ERK), ERK, p-p38 and p38 were purchased from Cell Signaling Technology (Danver, MA, USA). Anti- $\gamma$ H2A histone family, member X ( $\gamma \mathrm{H} 2 \mathrm{AX})$ antibody was purchased from Millipore (Billerica, MA, USA). The angiogenesis inhibitor SU5416 was synthesized at Sugen Inc. as previously described (8). For in vitro experiments, SU5416 was dissolved in DMSO as a $2 \mathrm{mmol} / \mathrm{l}$ stock solution that was stored at $-20^{\circ} \mathrm{C}$.

Cell culture. The human colorectal cancer cell lines HT29 and HCT116 were grown in Roswell Park Memorial Institute (RPMI)-1640 medium supplemented with $10 \%$ fetal bovine 
serum (FBS), glutamine, HEPES and antibiotics at $37^{\circ} \mathrm{C}$ in a $5 \% \mathrm{CO}_{2}$ humidified incubator.

Irradiation. Cells were plated in $60-\mathrm{mm}$ dishes and incubated at $37^{\circ} \mathrm{C}$ in a $5 \% \mathrm{CO}_{2}$ humidified incubator, and grown to $70-80 \%$ confluency. Cells were irradiated with a ${ }^{137} \mathrm{Cs} \gamma$-ray source (Atomic Energy of Canada, Ltd., Ontario, Canada) at a dose rate of $3.81 \mathrm{~Gy} / \mathrm{min}$.

Colony forming assay. SU5416 ( $2 \mu \mathrm{mol} / \mathrm{l})$ was preincubated for $24 \mathrm{~h}$ before radiation exposure and then incubated for a total of $72 \mathrm{~h}$. After 14-20 days, colonies were stained with $0.4 \%$ crystal violet (Sigma-Aldrich, St. Louis, MO, USA). The plating efficiency (PE) represents the percentage of seeded cells that grew into colonies under specific culture conditions for a given cell line. The survival fraction, expressed as a function of irradiation, was calculated as follows: survival fraction $=$ colonies counted $/($ cells seeded $\times \mathrm{PE} / 100)$. To evaluate the radiosensitizing effects of SU5416, the enhancement ratio was calculated as the dose (Gy) for radiation alone divided by the dose for radiation plus SU5416 that yielded a surviving fraction of $50 \%\left(\mathrm{D}_{50}\right)$.

Detection of apoptotic cells by Annexin V staining. After SU5416 exposure, the cells were treated with radiation for $48 \mathrm{~h}$. Cells were washed with ice-cold phosphate-buffered saline (PBS), trypsinized and resuspended in $1 \mathrm{X}$ binding buffer [10 mm HEPES/ $\mathrm{NaOH}(\mathrm{pH} 7.4), 140 \mathrm{~mm} \mathrm{NaCl}$ and $2.5 \mathrm{~mm}$ $\left.\mathrm{CaCl}_{2}\right]$ at $1 \times 10^{6}$ cells $/ \mathrm{ml}$. Aliquots $(100 \mu \mathrm{l})$ of the cell solution were mixed with $5 \mu \mathrm{l}$ Annexin V-fluorescein isothiocyanate (FITC) (BD Pharmingen) and $10 \mu \mathrm{l}$ propidium iodide (PI) stock solution $(50 \mu \mathrm{g} / \mathrm{ml}$ in PBS) by gentle vortexing, followed by a 15 -min incubation at room temperature in the dark. Cells were resuspended in $1 \mathrm{X}$ binding buffer $(400 \mu \mathrm{l})$ and analyzed on a FACScan flow cytometer (BD Biosciences, Franklin Lakes, NJ, USA). At least 10,000 cells were counted for each sample and data analysis was performed using CellQuest software (BD Biosciences).

Measurement of intracellular reactive oxygen species (ROS). The levels of intracellular ROS were assessed using the fluorescent probe 2',7'-dichlorofluorescein diacetate $\left(\mathrm{H}_{2} \mathrm{DCF}-\mathrm{DA}\right)$. The cells were then incubated with $10 \mu \mathrm{M} \mathrm{H}_{2}$ DCF-DA for $30 \mathrm{~min}$ at $37^{\circ} \mathrm{C}$, and the green fluorescence corresponding to the levels of intracellular ROS was detected through a 520-nm long-pass filter on an Olympus FV-1000 laser fluorescence microscope.

Senescence-associated $\beta$-galactosidase (SA- $\beta$-gal) assay. Colon cancer cells were washed twice in PBS, fixed at room temperature for 6-7 $\mathrm{min}$ in $2 \%$ formaldehyde $/ 0.2 \%$ glutaraldehyde, then washed three times in PBS and incubated at $37^{\circ} \mathrm{C}$ with SA- $\beta$-gal staining solution $[1 \mathrm{mg} / \mathrm{m}$; 5 -bromo-4-chloro-3indolyl $\beta$-D-galactoside (Sigma-Aldrich)] in buffer containing $100 \mathrm{mM}$ citric acid, $200 \mathrm{mM}$ sodium phosphate, $5 \mathrm{mM}$ potassium ferrocyanide, $5 \mathrm{mM}$ potassium ferrocyanide, $150 \mathrm{mM}$ $\mathrm{NaCl}$ and $2 \mathrm{mM} \mathrm{MgCl}$ at $\mathrm{pH}$ 6.0. Staining was evident after 4-6 $\mathrm{h}$. The cells were washed with PBS and then with distilled water before microscopic examination. Cells at passage 14 were used as a control.
Analysis of cell cycle progression. Cells were seeded in $60-\mathrm{mm}$ dishes with $60 \%$ confluency. After $24 \mathrm{~h}$, cells were trypsinized, harvested, and fixed in $1 \mathrm{ml}$ of $70 \%$ cold ethanol in test tubes and incubated at $4{ }^{\circ} \mathrm{C}$ for overnight. After incubation, cells were centrifuged at 2,000 rpm for $3 \mathrm{~min}$, and the cell pellets were resuspended in $500 \mu \mathrm{l}$ propidium iodine $(10 \mu \mathrm{g} / \mathrm{ml})$ containing $300 \mu \mathrm{g} / \mathrm{ml}$ RNase (Sigma, MO, USA). Cell cycle distribution was calculated from 10,000 cells with CellQuest software using FACScaliber (both from Becton Dickinson, CA, USA).

Immunohistochemistry. Immunohistochemistry was performed to determine the nuclear distribution of $\gamma$-H2AX in individual cells. Cells were grown on chamber slides for 1 day before irradiation or SU5416 treatment. For combination treatment, SU5416 was added to the cells before the radiation treatment. All treatments were performed while cells were attached to the slides. After treatment, the cells were fixed in $4 \%$ paraformaldehyde and permeabilized with $0.7 \%$ Triton X-100 in PBS. After blocking with $10 \% \mathrm{FBS} / 1 \%$ bovine serum albumin for $1 \mathrm{~h}$, detection was performed using a 1:1,000 dilution of a FITC-labeled mouse monoclonal $\gamma$-H2AX antibody (Millipore).

Western blotting. Colon cancer cells were exposed to SU5416 and then treated with radiation for 1 and $24 \mathrm{~h}$. The cells were lysed using radioimmunoprecipitation assay buffer, and equal amounts of proteins were separated by SDS-polyacrylamide gel electrophoresis and transferred to nitrocellulose membranes. The membranes were blocked with $1 \%$ (v/v) non-fat dry milk in Tris-buffered saline with $0.05 \%$ Tween-20 and then incubated with the indicated antibodies. Blots were incubated with primary antibodies at 1:1,000 dilutions and with secondary antibodies at 1:5,000 dilutions. Immunoreactive protein bands were visualized by enhanced chemiluminescence (Amersham Biosciences, Piscataway, NJ, USA) and scanned.

Wound healing scratch assay. Human colon cancer cells were seeded onto 6-well plates (Corning, Corning, NY, USA) at $2.5 \times 10^{4} /$ well in $3 \mathrm{ml}$ RPMI-1640 medium supplemented with $10 \%$ FBS. At 2 days, the monolayers were disrupted mechanically using a sterile $200 \mu \mathrm{l}$ tip. The assay was performed in duplicate. The wells were photographed every $24 \mathrm{~h}$. Cells were then stained with $0.2 \%$ crystal violet. Cell migration was monitored using a Nikon Eclipse Ti microscope with a DS-Fi1 camera. The cells were counted using ImageJ software (United States National Institutes of Health, Bethesda, MD, USA).

Invasion assay. The invasive ability of the cells in vitro was measured using a Transwell invasion assay kit (Chemicon, Millipore, Norcross, GA, USA) according to the manufacturer's protocol. Briefly, cells were seeded onto the membrane of the upper chamber of the Transwell at a concentration of $4 \times 10^{5} / \mathrm{ml}$ in $150 \mu \mathrm{l}$ serum-free RPMI medium and were left untreated or were treated with the indicated doses of SU5416, radiation, or a combination of the two. The medium in the lower chamber contained $10 \%$ FBS as a source of chemoattractants. After incubation for $24 \mathrm{~h}$, the cells that passed through the Matrigel-coated membrane were stained with a cell stain solution containing crystal violet and photographed. 
A

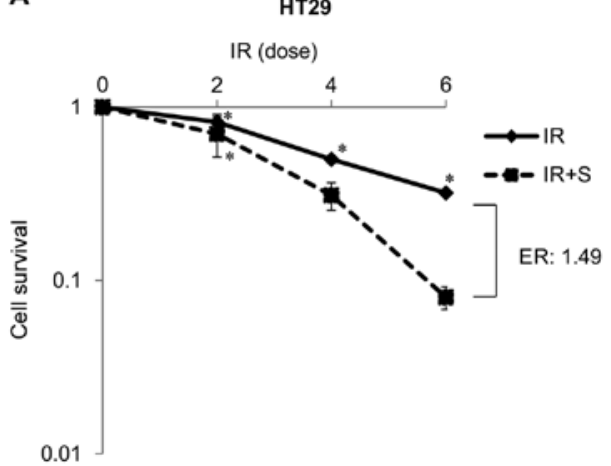

B

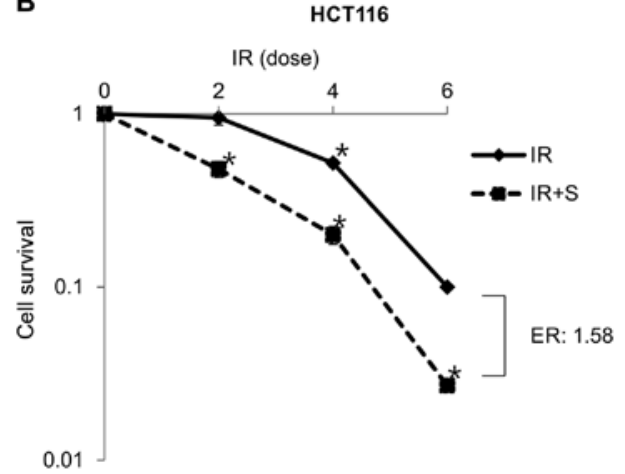

Figure 1. Radiosensitizing effects of SU5416 on colon cancer cells. The radiosensitivity of (A) HT-29 and (B) HCT116 cell lines treated with (dashed line) and without (solid line) SU5416 (S) $(2 \mu \mathrm{mol} / 1)$ before radiation (IR) was measured by colony forming assay. Values represent the means of three experiments \pm SE; ${ }^{*} \mathrm{p}<0.05,{ }^{* *} \mathrm{p}<0.001$. ER, enhancement ratio.
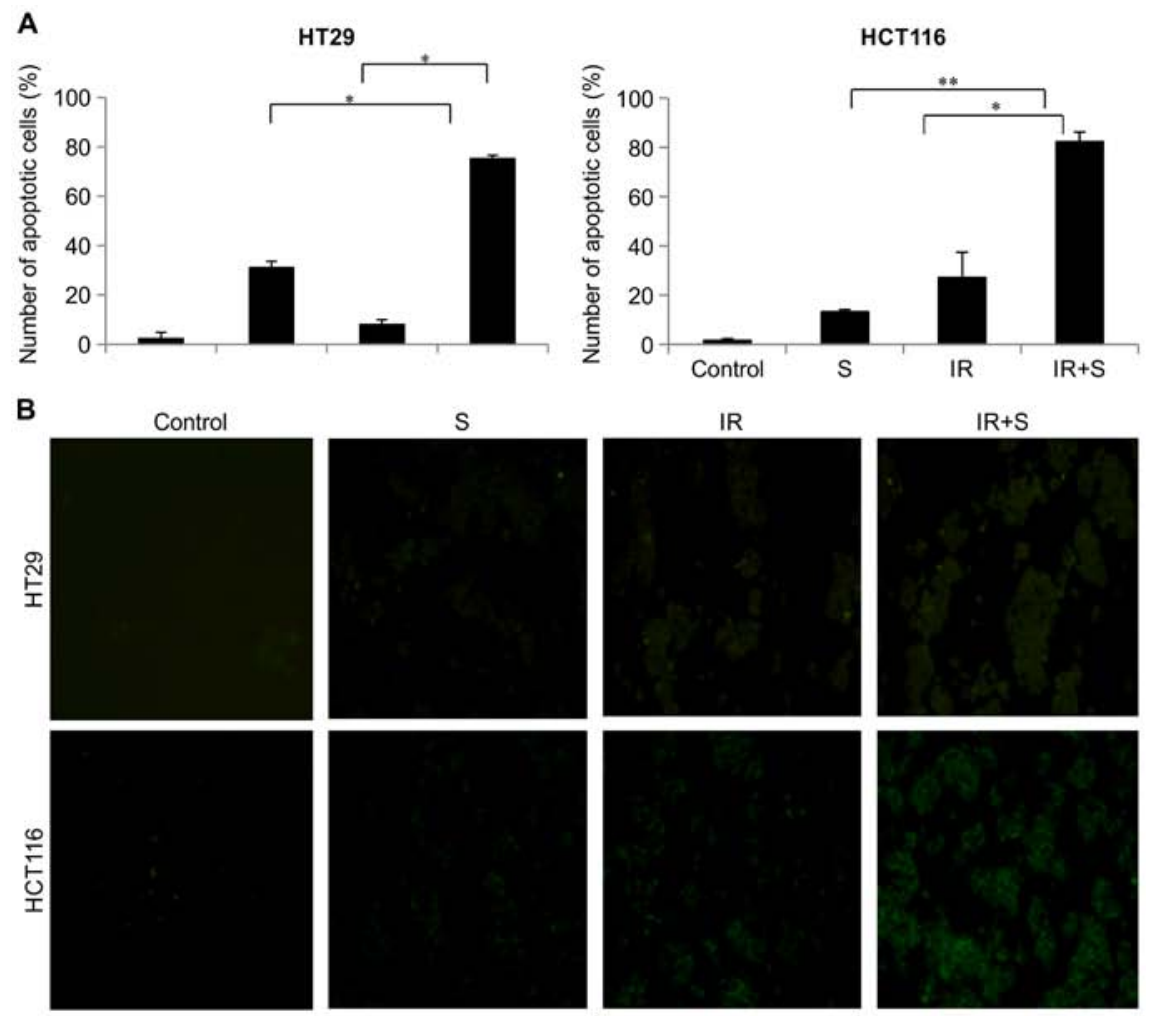

C

S

IR

$\mathrm{IR}+\mathrm{S}$
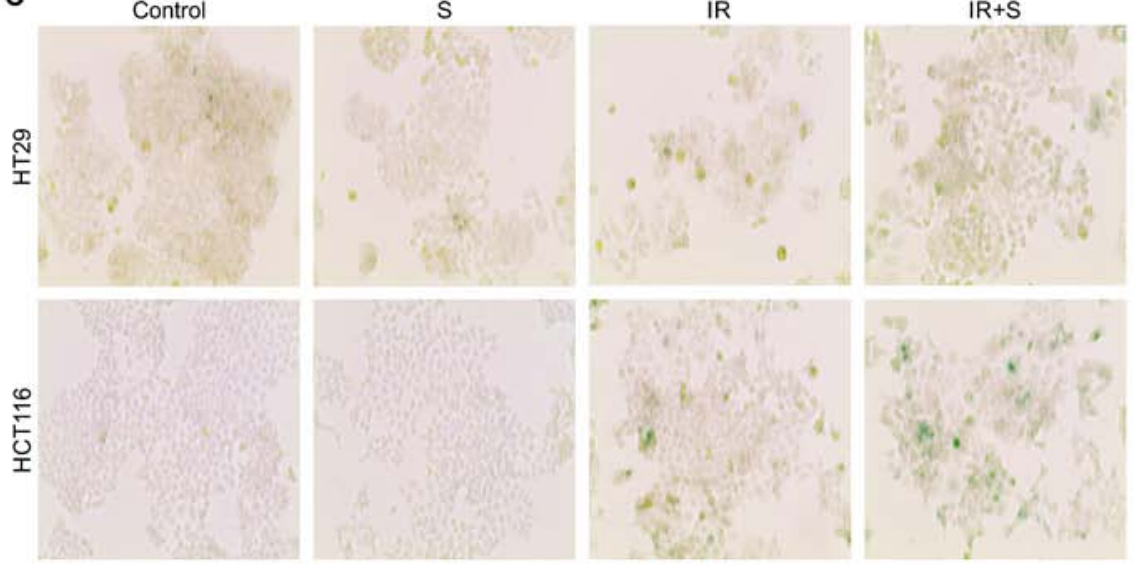

Figure 2. Effects of SU5416 and radiation on the apoptosis of colon cancer cells. (A) HT-29 and HCT116 cell lines were exposed to SU5416 (S) (2 $\mu$ mol/1) and/or 5 Gy of radiation (IR) for $72 \mathrm{~h}$ and analyzed by Annexin V staining. Values represent the means \pm SE of three experiments; ${ }^{*} \mathrm{p}<0.05,{ }^{* *} \mathrm{p}<0.001$. (B) HT-29 and HCT116 cells were treated with SU5416, radiation or the indicated combinations, and ROS levels were determined by 2',7'-dichlorofluorescein diacetate, a peroxide-sensitive dye, during the final $30 \mathrm{~min}$ of incubation. The intracellular levels of ROS were detected by confocal laser fluorescence microscopy. (C) Staining for senescence-associated $\beta$-galactosidase (SA- $\beta$-gal). Positive staining for SA- $\beta$-gal was detected 3 days after $\mathrm{NaCl}$ elevation. 
A
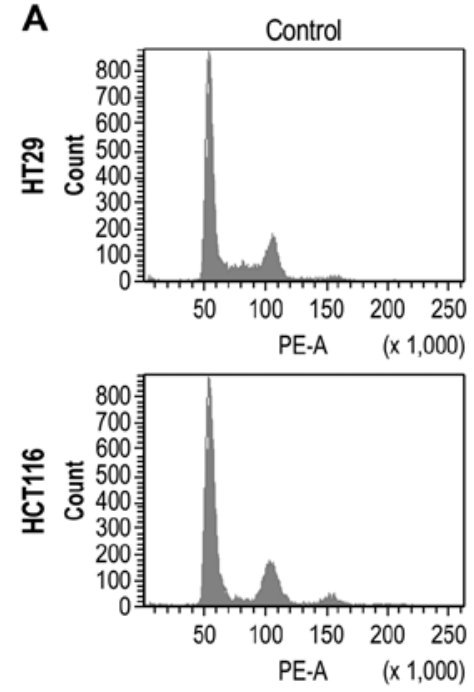

S
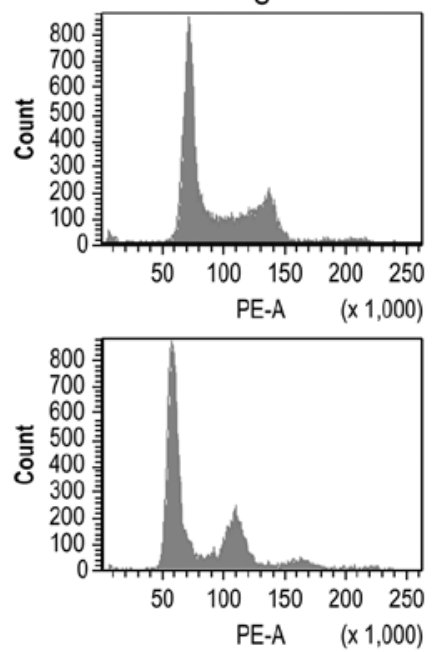
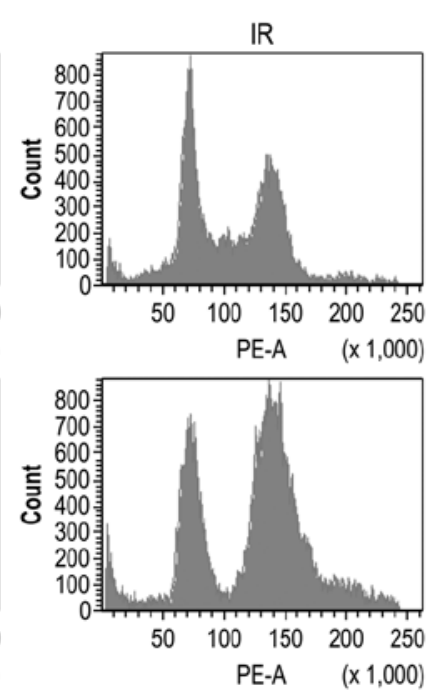
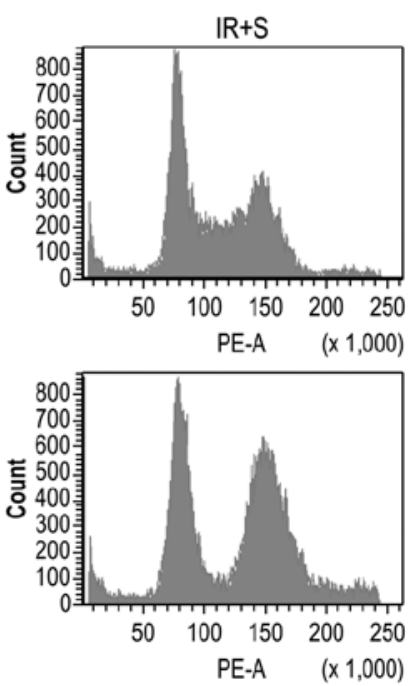

B
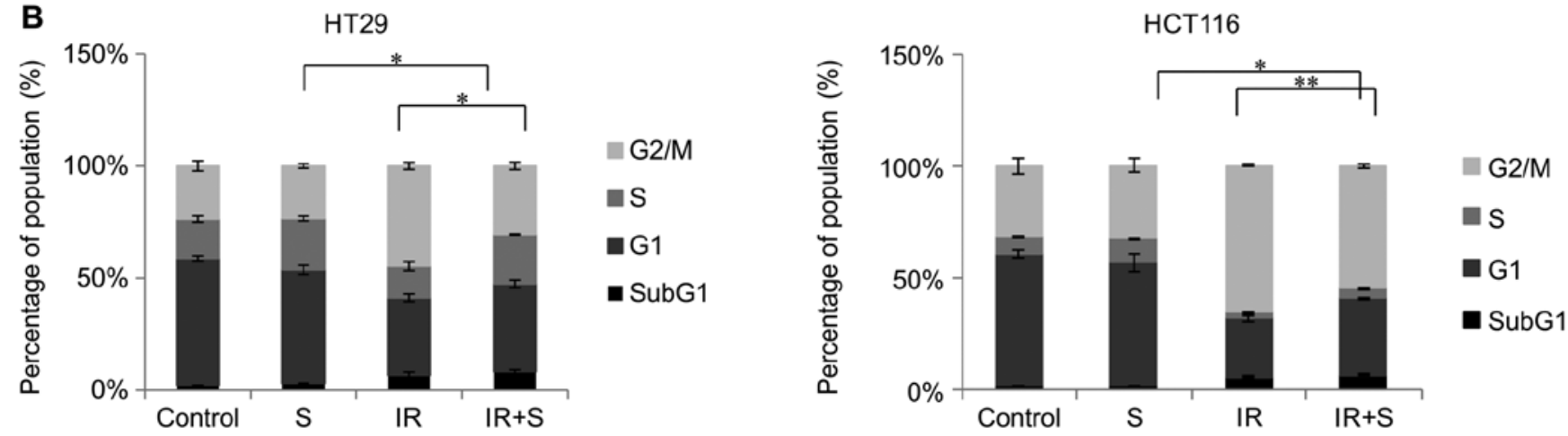

Figure 3. SU5416 blocks cell cycle progression in the irradiated cells at the G2-M phase. (A) HT-29 and HCT116 cells were treated with $2 \mu$ M SU5416 (S) and/or $5 \mathrm{~Gy}$ radiation (IR) for $24 \mathrm{~h}$ and flow cytometric analysis of PI-stained cells was carried out. (B) The cell cycle distribution was analyzed quantitatively. ${ }^{*} \mathrm{p}<0.05,{ }^{* *} \mathrm{p}<0.001$.

Statistical analysis. Statistical significance was determined by the Student's t-test. Differences were considered significant if the p-value was $<0.05$ or 0.001 .

\section{Results}

Radiosensitizing effect of SU5416 on colon cancer cell proliferation. To investigate whether SU5416 treatment sensitizes colon cancer cells to ionizing radiation(IR)-induced cell killing, we conducted a clonogenic survival assay. Fig. $1 \mathrm{~A}$ and B shows the radiation dose-response curves of radiosensitive HCT116 cells and radioresistant HT29 cells irradiated with $\gamma$-rays in the presence of SU5416. The survival rate decreased to a greater extent for cells treated with SU5416 before irradiation compared with cells irradiated without SU5416, suggesting that SU5416 acts as a potential radiosensitizer to increase the sensitivity of colon cancer cells to IR-induced cell killing. The SU5416 effect, expressed as the enhancement ratio compared with radiation alone was calculated at $\mathrm{D}_{50}$.

SU5416 enhances radiation-induced senescence and apoptosis. To further explore the mechanisms by which SU5416 increases the radiation sensitivity of colon cancer cells, we investigated whether SU5416 promotes IR-induced senescence and apoptosis. We performed staining of the early apoptotic markers Annexin V and PI in colon cancer cell lines; radiation and SU5416 combination treatment for $72 \mathrm{~h}$ significantly increased the percentage of early apoptotic cells (Fig. 2A). To investigate the relationship between ROS production and enhancement of radiation-induced apoptosis by SU5416, we examined the effects of SU5416 on ROS production in colon cancer cells. ROS production was induced to a greater extent by the combination of SU5416 and radiation than by SU5416 or radiation alone (Fig. 2B). Recent studies have shown that IR induces premature senescence in cancer cells in a dose-dependent manner, suggesting that the induction of senescence plays an important role in IR-induced tumor suppression (9). We stained cells for SA- $\beta$-gal and found that the expression of SA- $\beta$-gal correlated with the loss of proliferation and was observed after approximately 5 days of exposure to various doses (Fig. 2C). The results showed that combined treatment with SU5416 and IR induced more SA- $\beta$-gal-positive senescent colon cancer cells than did either SU5416 or IR treatment alone (Fig. 2C). These results suggest that SU5416 may radiosensitize colon cancer cells by enhancing IR-induced premature senescence and apoptosis.

Effects of SU5416 and radiation on cell cycle phase distribution. To further investigate the mechanisms underlying the cell cycle after treatment with SU5416, we performed flow 


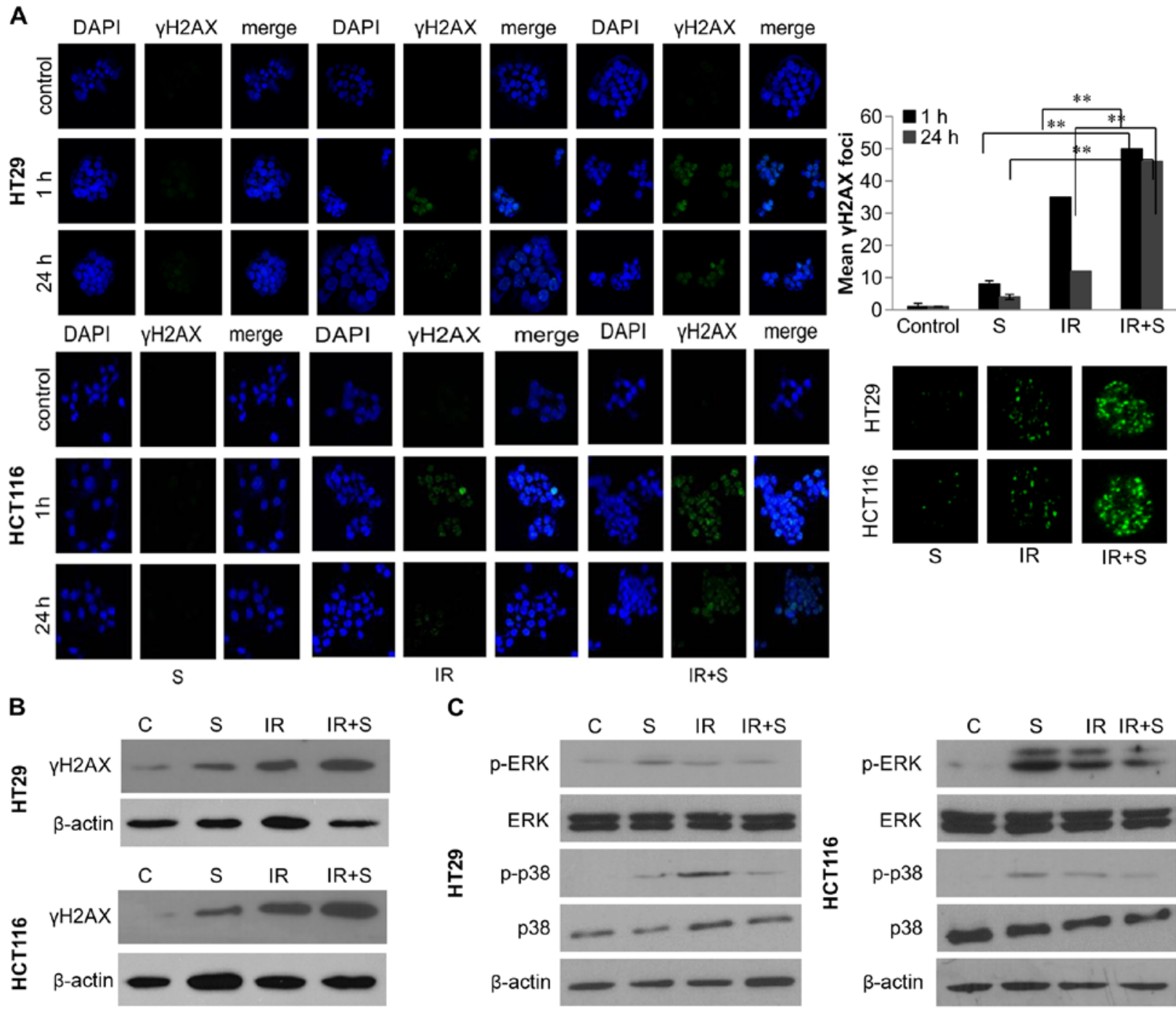

Figure 4. Effects of SU5416 on the DNA damage response in irradiated colon cancer cells. (A) Immunocytochemical staining of H2AX phosphorylation (Ser139) (green) in HT-29 and HCT116 cells at various time points after treatment with radiation (IR) and/or SU5416 (S). ${ }^{*}$ p $<0.05,{ }^{* *} \mathrm{p}<0.001$. (B and C) Lysates of cells treated with SU5416 (S), radiation (IR) or SU5416 with radiation (IR+S) were analyzed by western blotting using the indicated antibodies.

cytometric analysis of PI-stained cells in the two colon cancer cell lines (Fig. 3A). As shown in Fig. 3B, the sub-G1 phase indicating the apoptotic population was not markedly altered after treatment with SU5416 alone; however, combined treatment caused slight accumulation of cells in the sub-G1 phase. Combination therapy caused a decrease in cells in the $\mathrm{G} 2 / \mathrm{M}$ phase, suggesting efficient induction of cell cycle arrest at the $\mathrm{G} 2 / \mathrm{M}$ phase in both colon cancer cell lines.

Effect of SU5416 on radiation-induced DNA damage and mitogen-activated protein kinase (MAPK) expression. To analyze the effect of SU5416 on DNA double-strand break (DSB) processing, the level of phosphorylated H2AX $(\gamma-\mathrm{H} 2 \mathrm{AX})$, a marker of DSBs, was examined by immunohistochemistry and western blotting at 0,1 and $24 \mathrm{~h}$ after treatment. As shown in Fig. 4, prolonged expression of $\gamma-\mathrm{H} 2 \mathrm{AX}$ was observed $24 \mathrm{~h}$ after radiation exposure in the presence of SU5416 (Fig. 4A and B). Two MAPK members, ERK and p38, are involved in DNA damage responses (10). However, it has yet to be determined if SU5416 treatment affects the activities of ERK and p38 in colon cancer cells. To address this issue, western blot analyses were performed to assess the expression levels of p-ERK, ERK, p-p38 and p38 in the colon cancer cells. The results showed that SU5416 treatment significantly inhibited the expression levels of p-ERK and p-p38 in the irradiated colon cancer cells (Fig. 4C).

Combination therapy significantly inhibits tumor cell motility and tumor cell invasion. Cell migration and invasion play crucial roles in tumor metastasis (11). To further investigate the antimetastatic effect of SU5416, the ability of SU5416-treated colon cancer cell migration was assessed by scratch-wound and Transwell assays. The results from the scratch-wound assay showed that the wound healing of the combination treatment was gradually reduced compared with the wound healing ability of the cells treated with SU5416 or radiation alone (Fig. 5A and B). We next investigated the anti-invasive and anti-migratory activities of SU5416 on colon cancer cells using a Transwell system. As shown in Fig. 5, SU5416 in combination with radiation significantly inhibited the migration and invasion of the two colon cancer cell lines in the chamber Transwell assays (Fig. 5C-F). These results 

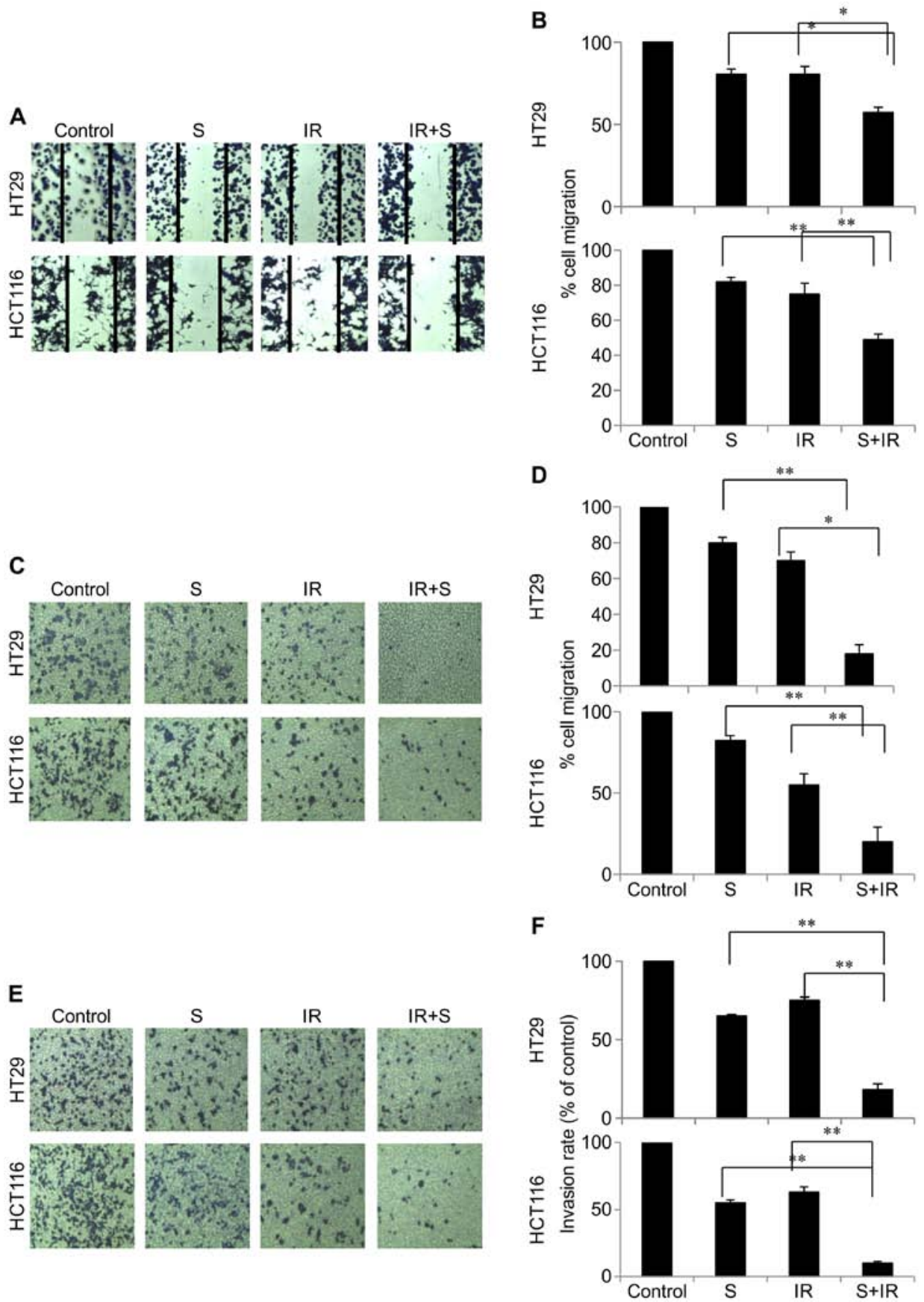

Figure 5. Effect of SU5416 and radiation on the invasion and migration of colon cancer cells. (A and B) Migration of colon cancer cells was examined by scratch assay. Each assay was photographed, and the distances between the migrating cell edges were quantified. Data are expressed as the percentage of cell migration. Values represent the means of three experiments $\pm \mathrm{SE}$; ${ }^{*} \mathrm{p}<0.05,{ }^{*} \mathrm{p}<0.001$. (C-F) Tumor cell migration $(\mathrm{C}$ and $\mathrm{D})$ and invasion $(\mathrm{E}$ and $\mathrm{F})$ was examined by gelatin migration and Matrigel invasion assays. The number of tumor cells that invaded the gelatin and Matrigel was counted in five high-power fields. Values represent the means of three experiments $\pm \mathrm{SE} ;{ }^{*} \mathrm{p}<0.05,{ }^{* *} \mathrm{p}<0.001$. Data are expressed as amplified pictures for $\gamma$-H2AX foci.

suggest that the combination of SU5416 and radiation affected the abilities of cell migration and invasion.

\section{Discussion}

Numerous patients who experience radiotherapy develop local failure. To improve the efficacy of treatment and reduce sideeffects, there is an increasing interest in various combinations of radiotherapy using novel targeted therapies (12). Among them, inhibition of tumor angiogenesis is one such targeted therapy. The importance of angiogenesis in the progression of human cancers has been highlighted by recent studies that have associated angiogenic phenotypes with patient survival (13). Growing tumors induce angiogenesis to ensure an adequate delivery of oxygen and nutrients, and several angiostatic drugs have been approved for the treatment of cancer patients. Preclinical studies suggest that anti-angiogenic agents enhance tumor control in response to radiation (14), and large numbers of such compounds are already in clinical studies or have been approved for the treatment of certain malignancies (15). Both pre-clinical and clinical studies have shown that radiotherapy can affect tumor angiogenesis and that inhibition of 
angiogenesis can potentiate the effect of radiotherapy. Thus, inhibition of angiogenesis combined with radiotherapy is a promising strategy for cancer therapy. In the present study, we showed that the combination of VEGF signaling inhibition and radiation significantly enhanced the antitumor effects of each monotherapy in colon cancer cells.

For these studies, we used SU5416 as an inhibitor of VEGF signaling in colon cancer cells. Recent clinical studies have shown that SU5416 is active against metastatic colorectal cancer when combined with fluorouracil/leucovorin (16). Recent clinical studies have also shown that the combination of SU5416 and radiation may provide clinical benefits in patients with certain cancer cell types (17). However, it is largely unknown how SU5416 treatment may affect IR-induced sensitivity of colon cancer cells. Therefore, the aim of the present study was to explore the molecular mechanisms of potential SU5416 treatment-induced sensitization of colon cancer cells to radiotherapy. In the present study, we provide a scientific rationale for the clinical application of SU5416 as a radiosensitizer in colorectal cancer by evaluating the effect of single and combined treatments on tumor cell survival, apoptosis, senescence, cell cycle regulation, DNA repair activity and tumor cell invasiveness. Our investigations demonstrated that SU5416 combined with radiation significantly decreased clonogenic survival and that SU5416 enhanced the radiosensitivity of colon cancer cells by promoting apoptosis through ROS (Figs. 1 and 2). Senescence is a critical mechanism underlying chemotherapy and radiotherapy-induced tumor suppression. Therefore, we demonstrated that SU5416 treatment markedly increased SA- $\beta$-gal staining in the irradiated colon cancer cells, suggesting that SU5416 may sensitize colon cancer cells to radiotherapy via enhancing IR-induced premature senescence (Fig. 2C). In addition, when SU5416 was administered before radiation, the colon cancer cells failed to undergo mitosis. This SU5416-mediated inhibition of cell cycle progression appeared to be caused by failure of the cells to undergo transition from the G2 to M phase (Fig. 3). The critical mechanism of tumor cell killing by IR is DNA damage and, most significantly, DSBs (18). The rationale for using cytotoxic chemotherapy as a radiosensitizer is based on the rationale that additional DNA damage may lower the threshold of cell death induced by IR. Our results showed that the combination treatment delayed the clearance of $\gamma-\mathrm{H} 2 \mathrm{AX}$, suggesting that SU5416 maintains DNA damage and thus, increases the radiosensitivity of cells (Fig. 4).

Migration is a main event in the metastatic cascade of cancers, and expression of VEGF-2 plays an important role in cell migration by activating a number of intracellular signaling pathways (19-21). Therefore, we examined the effect of our combination therapy on the migratory characteristics of colon cancer cells. Our data showed that the combination treatment effectively inhibited tumor cell invasion and migration mediated by a Transwell chamber assay (Fig. 5). VEGF mediates angiogenesis predominantly via the activation of PI3K/Akt and MAPK signaling cascades (22). ERK and p38 are key downstream components of the RAF/MEK/ERK signaling pathway, and aberrant signaling can promote cell immortalization, proliferation and resistance to radiation (22). Fig. 4 shows that radiation-activated p-ERK and p-p38 expression were suppressed by pre-irradiation treatment with SU5416.
Taken together, our results demonstrated for the first time that SU5416-induced radiosensitization is associated with inhibition of tumor cell survival, marked increases in ROS production, senescence induction, DNA DSBs and tumor cell invasiveness in irradiated colon cancer cells, suggesting that increased IR-induced premature senescence could be exploited as a novel strategy to sensitize colon cancer cells to radiotherapy. Our data provide a molecular biological basis for the use of chemoradiation to enhance the therapeutic efficacy against colon cancer cells. For future research, in vivo mouse models and evaluation of toxicity to normal cells should be conducted to determine the clinical applications of SU5416 and minimize complications.

\section{Acknowledgements}

The present study was supported by the National Research Foundation of Korea (NRF) grants (NRF-2014R1A1A3053958 and NRF-2014029534) funded by the Korean government (MSIP).

\section{References}

1. Krook JE, Moertel CG, Gunderson LL, Wieand HS, Collins RT, Beart RW, Kubista TP, Poon MA, Meyers WC, Mailliard JA, et al: Effective surgical adjuvant therapy for high-risk rectal carcinoma. N Engl J Med 324: 709-715, 1991.

2. Seiwert TY, Salama JK and Vokes EE: The concurrent chemoradiation paradigm - general principles. Nat Clin Pract Oncol 4: 86-100, 2007.

3. Siemann DW, Bibby MC, Dark GG, Dicker AP, Eskens FA, Horsman MR, Marmé D and Lorusso PM: Differentiation and definition of vascular-targeted therapies. Clin Cancer Res 11: 416-420, 2005.

4. Jubb AM, Pham TQ, Hanby AM, Frantz GD, Peale FV, Wu TD, Koeppen HW and Hillan KJ: Expression of vascular endothelial growth factor, hypoxia inducible factor $1 \alpha$, and carbonic anhydrase IX in human tumours. J Clin Pathol 57: 504-512, 2004.

5. Fong TA, Shawver LK, Sun L, Tang C, App H, Powell TJ, Kim YH, Schreck R, Wang X, Risau W, et al: SU5416 is a potent and selective inhibitor of the vascular endothelial growth factor receptor (Flk-1/KDR) that inhibits tyrosine kinase catalysis, tumor vascularization, and growth of multiple tumor types. Cancer Res 59: 99-106, 1999.

6. Huber PE, Bischof M, Jenne J, Heiland S, Peschke P, Saffrich R, Gröne HJ, Debus J, Lipson KE and Abdollahi A: Trimodal cancer treatment: Beneficial effects of combined antiangiogenesis, radiation, and chemotherapy. Cancer Res 65: 3643-3655, 2005.

7. Bischof M, Abdollahi A, Gong P, Stoffregen C, Lipson KE, Debus JU, Weber KJ and Huber PE: Triple combination of irradiation, chemotherapy (pemetrexed), and VEGFR inhibition (SU5416) in human endothelial and tumor cells. Int J Radiat Oncol Biol Phys 60: 1220-1232, 2004.

8. Krystal GW, Honsawek S, Kiewlich D, Liang C, Vasile S, Sun L, McMahon G and Lipson KE: Indolinone tyrosine kinase inhibitors block Kit activation and growth of small cell lung cancer cells. Cancer Res 61: 3660-3668, 2001.

9. Lu B, Geng L, Musiek A, Tan J, Cao C, Donnelly E, McMahon G, Choy $\mathrm{H}$ and Hallahan DE: Broad spectrum receptor tyrosine kinase inhibitor, SU6668, sensitizes radiation via targeting survival pathway of vascular endothelium. Int J Radiat Oncol Biol Phys 58: 844-850, 2004.

10. Kharbanda S, Saleem A, Shafman T, Emoto Y, Taneja N, Rubin E, Weichselbaum R, Woodgett J, Avruch J, Kyriakis J, et al: Ionizing radiation stimulates a Grb2-mediated association of the stress-activated protein kinase with phosphatidylinositol 3-kinase. J Biol Chem 270: 18871-18874, 1995.

11. Leber MF and Efferth T: Molecular principles of cancer invasion and metastasis (Review). Int J Oncol 34: 881-895, 2009.

12. Begg AC, Stewart FA and Vens C: Strategies to improve radiotherapy with targeted drugs. Nat Rev Cancer 11: 239-253, 2011. 
13. Cherrington JM, Strawn LM and Shawver LK: New paradigms for the treatment of cancer: The role of anti-angiogenesis agents. Adv Cancer Res 79: 1-38, 2000.

14. Wachsberger P, Burd R and Dicker AP: Tumor response to ionizing radiation combined with antiangiogenesis or vascular targeting agents: Exploring mechanisms of interaction. Clin Cancer Res 9: 1957-1971, 2003.

15. Jain RK, Duda DG, Clark JW and Loeffler JS: Lessons from phase III clinical trials on anti-VEGF therapy for cancer. Nat Clin Pract Oncol 3: 24-40, 2006.

16. Stadler WM, Heimann R, Karczmar GS, Gajewski T, Kindler H, MacEaneny P, Zamora M, Medved M and Vokes E: Clinical evaluation of tumor angiogenesis markers in metastatic cancer. Proc Am Soc Clin Oncol 20: 382, 2001.

17. Timke C, Zieher H, Roth A, Hauser K, Lipson KE, Weber KJ, Debus J, Abdollahi A and Huber PE: Combination of vascular endothelial growth factor receptor/platelet-derived growth factor receptor inhibition markedly improves radiation tumor therapy. Clin Cancer Res 14: 2210-2219, 2008.
18. Bernier J, Hall EJ and Giaccia A: Radiation oncology: A century of achievements. Nat Rev Cancer 4: 737-747, 2004.

19. Brooks PC: Cell adhesion molecules in angiogenesis. Cancer Metastasis Rev 15: 187-194, 1996.

20. Basset P, Okada A, Chenard MP, Kannan R, Stoll I, Anglard P, Bellocq JP and Rio MC: Matrix metalloproteinases as stromal effectors of human carcinoma progression: Therapeutic implications. Matrix Biol 15: 535-541, 1997.

21. Johnsen M, Lund LR, Rømer J, Almholt K and Danø K: Cancer invasion and tissue remodeling: Common themes in proteolytic matrix degradation. Curr Opin Cell Biol 10: 667-671, 1998.

22. Roberts PJ and Der CJ: Targeting the Raf-MEK-ERK mitogenactivated protein kinase cascade for the treatment of cancer. Oncogene 26: 3291-3310, 2007. 